\title{
The Landscape of Civil Society Organizations in the Economy of Kosovo
}

\author{
K. VLLASAJ \\ University of Debrecen, Faculty of Economics and Business, Károly Ihrig Doctoral School of Management and \\ Business, Ph.D. Student, kushtrim.vllasaj@outlook.com
}

Abstract. Civil society organizations (CSOs) in the scientific literature have been studied broadly from various aspects such as cultural, political, social and economic. But as far as the last one is concerned, there is still a research gap because there is a lack of study about their contribution to economies under development, such as Kosovo, and which must be filled because of its importance. This paper tends to analyze the present situation of CSOs in Kosovo and their potential contribution to economic activity. Highlighting the activities, the structure and the place of these organizations in the economy will be the approach, in the beginning, to pave the way for further study of specific areas related to them. The methodology established contains analyses of secondary sources that are done by using data from the Ministry of Public Administration of Kosovo, Kosovar Index of Civil Society which is a regular report of the Kosovar Civil Society Foundation (KCSF), and other supplementary data. However, this will proceed after the scientific conceptual issues of CSOs and their place within the economy. Finally, the results show that civil society in Kosovo is very diverse with organizations in different sectors, and the economic activity sector consists of mostly agricultural NGOS. In transition countries, CSOs are seen as an alternative that improves a particular sector. Thus far, there are over 10,000 organizations established in Kosovo, but relative studies suggest only 1000 to be active. Furthermore, their activity and contribution to economic development is little known so far, while the main problem of the economy remains unemployment.

Keywords: civil society organizations, civil society, economy, development, Kosovo.

\section{Introduction}

In the last decade, the interest in discussing these topics has been on the rise as certain phenomena became an objective actor that occupies a large place in society, and the need to study them in more depth grows. This paper attempts to present the civil society organizations sector in Kosovo from a general economic approach because even in Kosovo these organizations have an increasing trend and their role is becoming more prominent. After the 1999 war in Kosovo, in the period of the so-called "NGO blooming", the role of these organizations was naturally concentrated on reconstruction, peace, democracy, and state-building. However, their role should naturally change with their evolution over the years to keep them relevant for the time in which they exist by addressing current problems in Kosovo, one of which remains unemployment. Thus, when the government fails to make policies to reduce unemployment and the private sector lacks the capacity to provide employment to citizens, an alternative solution often comes from the third sector. The main points to be explored will be: the main economic sectors of NGOs activity, the relationship between NGOs and economic development, and the impact of NGOs on employment. 
The paper will be constructed in a manner that first sections will include the literature starting from civil society in general, civic organizations as entities and their features from various explanations. Secondly, will be continued with their historic creation, evolution and economic impact worldwide, especially related to employment development. Then, this sector will be analyzed from Europe and Balkan point of view, to see how the relationship is, how they treat the third sector and how is this rewarded to them. Finally, since the paper aims to present the place of CSOs in the economy and unemployment presents a major problem in economic development, the Kosovo case will be approached in this respect.

The analysis of these problems is mainly based on secondary sources. The first platform to be used is the list of NGOs registered by the Kosovo Ministry of Public Administration (MPA), which is official and relevant because it is updated when a new organization registers and the second platform is Kosovo Agency of Statistics (KAS). Another source usable for our analysis will be the Kosovar Index of Civil Society which is a report made by the Kosovar Civil Society Foundation (KCSF), an organization that serves as a leading actor in strengthening and funding civil society in Kosovo and in addition they have been measuring these issues regularly.

\section{Concepts and history of civil society organisations}

Regarding the explanation of the definitions and terms used to address the sector where CSOs exist, it can be said that it is very complex. Complexity refers to the ambiguity and inability to distinguish or differentiate between different terms such as "the third sector", "the civil society sector", "nongovernmental organizations (NGOs)", "non-profit organizations (NPOs)", etc. If we make a detailed analysis of each of these terms and compare them with each other, we can find differences, on the other hand, we can also use them as synonyms. And that is precisely what makes their right explanation difficult. In the International Classification of Non-profit Organizations (ICNPO), Salamon and Anheier [1] agreed that to distinguish them from their differences, first, it is necessary to present five basic features that these organizations share. They have to be: 1. Organized - institutionalized to some extent. 2. Private - institutionally separate from government. 3. Self-governing - equipped to control their activities. 4. Non-profit distributing - not returning profits generated to their owners or directors. and 5. Voluntary - involving some meaningful degree of voluntary participation.

But this is contested by many authors as they do not think that these organizations should have all these features necessarily. Gordanker and Weiss [2] do not include the feature related to volunteering, which brings these organizations closer to the other two sectors. On the other hand, if we look at this concept in the geographical dimension, we can certainly see differences in their definition and classification. Evers and Laville [3] call "American" the model proposed by Salamon and Anheier [1], proposing a different model called "European". The "European" definition of the third sector has an analytical approach of developing association typologies and changes in the development of the economic dimension of all non-profit organizations, furthermore, it includes cooperatives and mutual aid societies. While the "American" definition of the third sector is based more on a classificatory approach 
centered on a statistical interpretation of the sector comprising all non-profit organizations, plus, it excludes cooperatives and mutual aid societies.

Notwithstanding the interpretations, community organizations in different societies existed long ago without being noticed and without getting much attention, in this wise as formal organizations they were little known until the 1970s. This period is characterized by a small number of NGOs, which were mostly based on religious assistance and in short term relief. But the late 1970s and early 1980s was the period when NGOs were seen as real alternatives to bringing bright development projects with innovative technology and new ideas of addressing poverty[4][5]. In the mid-1990s, the development discourse shifted towards democratization discourse [5] as governments came to the center and NGOs were seen more as heroic organizations seeking to "do good" in difficult circumstances, but at the beginning of the 21st century, this impression has maturated in some form [6]. Although these organizations have been associated with the lack of proper recognition in limited development processes, since 2010 there has been an increase in their recognition as only some organizations within civil society that need to reorient themselves to their grassroots-roots [7].

In addition to the social, cultural, political arguments on the rationale for CSOs, great importance for their study is based on the fact that they are a major economic force, which has ever been increasing. In 1995, NPOs were about a $\$ 1.1$ trillion industry that employed about 19 million full-time employees in 22 countries around the world which had data, compared to 3.3 million who worked in the largest private corporations [8]. About 15 years later, non-profit institutions represented about $\$ 2.2$ trillion in operating expenditures, which employ nearly 56 million full-time equivalent workers in 42 countries which had employment data [9]. In this regard, civic organizations are evolving bodies that adapt easily, creating jobs based on the circumstances in which they operate and the current needs of society, and these organizations now take a major place globally.

Despite their increasing prominence, their role in underdeveloped countries worldwide is essential to bring a developmental alternative with the primary objective of alleviating poverty. Their role is their encouragement to create different innovative programs or services, for and from the community participation and through their ideas to take some control in changing the situation, besides the government that fails to provide a solution [10]. This participation often means a situation where workers are required and inhabitants of the community get involved in the form of employees or volunteers. Another way of addressing this problem is to empower new entrepreneurs, usually small and medium-sized enterprises, through assistance in various forms.

\section{Material and methods}

The compilation of this paper will be based on so-called "multiple-source secondary data" [11], which is compiled by combining different sets of secondary sources. In our case, the two basic sets are the list of NGOs registered by the Kosovo Ministry of Public Administration (MPA), which is official and relevant because it is updated when a new organization registers and the Kosovar Index of Civil Society which is a report made by Kosovar Civil Society Foundation (KCSF), but other supplementary data which can contribute in the study will be taken into consideration. 
To analyze the data was used the so-called form "secondary analysis" [12]. This form means that certain data collected by someone else are analyzed and interpreted by someone else for the purpose of answering questions other than the primary one. When it comes to large samples, this form is much more convenient for the researcher because it serves readily available data, instead of collecting primary data from the beginning. The list of Kosovo NGO's was received from the website of the Ministry of Public Administration in an Excel file, then it was coded and processed in the SPSS (Statistical Program for Social Sciences) and presented through simple means of descriptive statistics.

\section{Discussion}

\subsection{The regulation and the environment of the third sector in Kosovo}

Kosovo's civil society activity is very problematic to describe as it is associated with problems at least on three levels. The problem at the primary level is that civil society consists of ordinary individuals and organizations that are difficult to translate into numbers. The second level problem is that nongovernmental organizations can function without being registered. And the third level problem is that the data of the relevant institutions are very deficient because they do not record the real up to date activity of NGOs, and the fact that the organization is considered active even if it does not perform regular activity. These problems make the activity of civil society and such organizations unreliable.

All civil society organizations in Kosovo are primarily titled as Non-Governmental Organizations (NGO's), although the law prescribes that they must be non-profit. The classic universal way of organizing, in Kosovo, has changed a little because, in addition to the association and foundation, the NGO can also be organized as an institute, under the new Law on Freedom of Association in NonGovernmental Organizations of 20191. To establish an association there must be 3 or more founders while establishing a foundation or institute can be done even by one person. Their registration infrastructure is very convenient as it can be done free of charge, although for the registration of foundation is required a declaration of the minimum initial capital of 1000 euros.

In a different context, another division in Kosovo is the division of local and foreign NGOs. Until the $15^{\text {th }}$ of October 2019, according to the latest official data, in Kosovo have been registered 10020 domestic and 545 foreign NGOs, since 1999 [13]. 95.8\% of local NGOs are registered as associations while 4.2\% are foundations. There are no organizations registered as institutes, as the law enabling this is relatively new. Most of them are located in urban areas $(83.5 \%$ of them declared their address in cities, more than $1 / 3$ of them in the capital city), while a smaller percentage of $14.7 \%$ in rural areas. One problem to note is that the number of truly active organizations is not indicated by the source where these data were obtained and by no other source. However, a study done by KCSF in 2018 [14] suggests that the number of truly active organizations is around 1,000.

As for the jobs generated by this sector, their exact number is unknown because there is no official data from the authority that is supposed to report on this issue. However, some other official data can be

\footnotetext{
${ }^{1}$ Law No. 06/L- 043 on Freedom of Association in Non-Governmental Organisations, Government of Kosovo, April 2019, Prishtina
} 
extracted from the Kosovo Pension Savings Trust (KPST) and the Kosovo Tax Agency, which can be taken as a good basis for the number of employees in the sector. According to KPST data, in 2018 certain NGOs provided pension contributions to 17,724 employees or $5.14 \%$ of the total number $(344,353)$ of active contributors in Kosovo [15]. Furthermore, employment in the civil society sector is more genderbalanced as it is almost equal ( $53.5 \%$ men, $46.5 \%$ women), compared to other sectors where women do not even represent $1 / 3$ of employment. Despite numerous challenges, such as lack of funds, lack of recognition of their authority, the poor institutional infrastructure of their regulation, CSOs in Kosovo are still a considerable generator contributing to the overall reduction of unemployment.

year periods

\begin{tabular}{|c|c|c|c|c|c|c|}
\hline field of & Social areas & 586 & 396 & 450 & 412 & 1844 \\
\hline \multirow[t]{10}{*}{ action } & Youth & 196 & 135 & 174 & 159 & 664 \\
\hline & Humanitarian & 144 & 124 & 90 & 84 & 442 \\
\hline & Health & 133 & 130 & 94 & 79 & 436 \\
\hline & Culture & 348 & 277 & 371 & 298 & 1294 \\
\hline & Sport & 112 & 554 & 390 & 558 & 1614 \\
\hline & Education and Science & 184 & 170 & 258 & 321 & 933 \\
\hline & Environment & 134 & 112 & 165 & 150 & 561 \\
\hline & Other & 282 & 152 & 135 & 131 & 700 \\
\hline & Agriculture and rural & 250 & 222 & 195 & 153 & 820 \\
\hline & Economic development & 192 & 141 & 210 & 169 & 712 \\
\hline Total & & 2561 & 2413 & 2532 & 2514 & 10020 \\
\hline
\end{tabular}

Table 1. The number of local newly set up NGO's in categories (field of action) * the year periods Crosstabulation Source: Formulated by the author using SPSS (MPA 2019)

The classification of NGOs into specific categories or fields of action was very difficult because their character/activity/focus is usually multiple. However, the categorization is done taking into account their primary activity.

Civic organizations are generally perceived as organizations that have such a character that brings about support and change in social areas. In Kosovo too, especially after the war in 1999-2004 in their blooming stage, the largest number of them (586) were of social character. The most expressed social areas were the society in general, democracy, justice, integration of minority ethnicities and gender equality. Youth empowerment is placed in a special category because of their large number. Another area that was quite popular and could be related to this period is the humanitarian. They were widespread throughout the territory, mostly in the form of charities, whether religious or other, and as 
it can be seen in the table, from 1999 to 2019 there was a downward trend of them. NGOs in the field of health have been present all the time, although their numbers have declined slightly in recent years. In the early, years their character has been more general or widespread in all areas of medicine, while in recent years there has been a growing registration of organizations in the psychosocial field.

A large number of them (1294) were also in the field of culture, most notably in music, art, languages and cultural traditions. Even sport as part of the culture but as a separate category is the primary topic of 1614 NGOs in Kosovo. They were mostly in the form of sports clubs, sport schools, fan groups and other forms that support the sport. The category of NGOs that have been on the rise is education and science, which includes organizations with informal educational, training, research, scientific and innovation topics. Environmental NGOs have been constant in numbers compared to the years when they were registered. And the Other category includes recreational groups, media related groups, law associations, state friendship associations, etc.

\subsection{The contribution of NGOs in economic sectors in Kosovo in four periods}

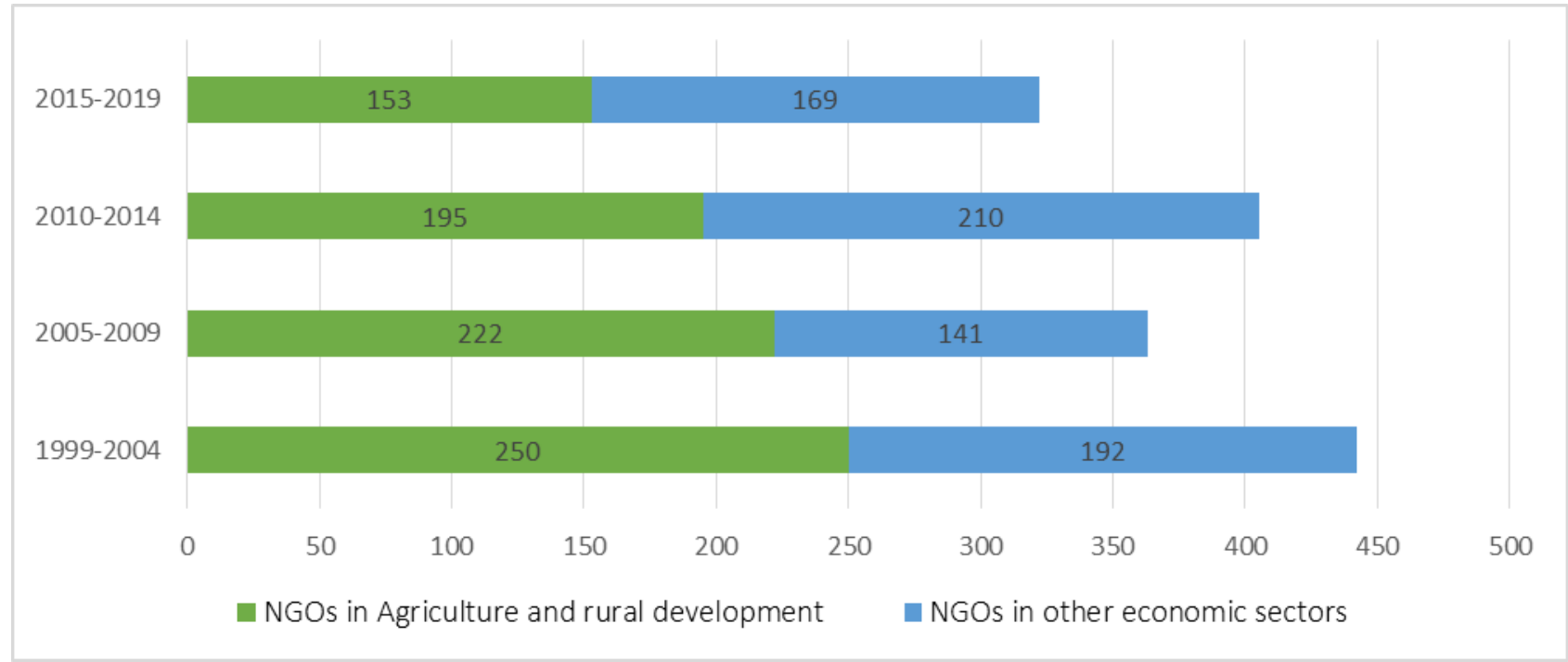

Chart 1. The number of local newly established NGOs related to economic development Source: Formulated by the author using Excel (MPA 2019)

The number of NGOs registered in Kosovo, in various areas of the three economic sectors ${ }^{2}$, is undoubtedly very large. Including agriculture and rural development in this category, their total number over the past 20 years, exceeds 1500. Agriculture is a large and important sector of the economy in Kosovo, as is the number of NGOs in this area. They have been operating and some of them continue to operate in various ways, from those formed by the farmers themselves, to those formed to support the farmers. During four periods, MPA has registered a total of 820 NGOs in the field of agriculture or rural development. The trend of their registration has generally declined, almost halving, from 250 in 2004 to 153 in 2019. During the period 2015-2019, the two most frequent organizing forms were associations

\footnotetext{
${ }^{2}$ The author is referring to the three-sector model which divides the economy into three sectors of activity: primary (extraction of raw products, mainly agriculture), secondary (manufacturing) and tertiary (services).
} 
aimed at advising, informing and encouraging farmers and associations of producers whose aim was to protect their interest in both the preservation and the sale of products.

A well-known case of an agricultural profile NGO in Kosovo is the Initiative for Agricultural Development of Kosovo (IADK). Their contribution is justifiably acknowledged since they have implemented 48 relatively big projects until 2015, funded by various donors such as EU, UNDP, USAID, Mercy Corps, Swiss Agency for Development and Cooperation (SDC), GIZ, and different church-based funding. Their activities are very diverse and continue to diversify with each passing year. Naturally, their primary activity is provision of advisory and training services. Not only do they provide advisory services to farmers, but now they offer those services to the ministry of agriculture as well, mostly in working strategic plans, rulemaking and law preparation. But their contribution is more than that as they provide support to livestock farmers, fruit and vegetable cultivation, food processing, market access, support on behalf of farmers towards central municipalities, various publications/reports on agriculture and many more other activities[16]. They continue direct support for farmers, young people, students, women and women's groups, the result of which is self-employment. In 2018, 151 beneficiaries have been supported with various grants, and 160 young people with essential work equipment [17].

\subsection{The European Union policy for Kosovo as part of the Balkans and Social Enterprises}

Like the countries of the region, Kosovo also aspires to become part of the European Union in the future. For this to happen, Kosovo needs to align and adapt its laws, policies, but also the real development stage of almost all sectors including awareness and development of civil society, respectively NGOs. In this context, the EU also provides financial assistance to Kosovo's civil society projects through the Instrument for Pre-Accession Assistance (IPA) and the European Instrument for Democracy and Human Rights (EIDHR). Such assistance is difficult to track what their contribution has been, but there have been recorded cases of successful projects.

For example, if we go back to the IADK case, we note that many projects funded by the European Union, usually lasting for a period of 2 years, (such as "Rural tourism for the economic development of the cross-border area of Kosovo and Montenegro", "Economic empowerment and capacity building of widows in Mitrovica and Prishtina region", "Promoting rural tourism and creating infrastructure in the Shale area", "Empowering civil society in policymaking in the agricultural sector") [17], have been implemented and their impact has been significant.

Another factor in this regard, which influences and contributes to social and economic development is the Social Enterprises (SE) sector. SEs lie somewhere between enterprises and CSOs, although they may be of both in some sense. In a synthesis report funded by the European Commission for Western Balkans, Rosandić [18] portrays the state of the social economy with the following characteristics. The 6 Western Balkan countries initially lack the basic strategic approach of this sector towards development. There is a low institutional understanding of the social economy concept and even lower engagement because institutions do not see it as a cross-sector theme. To change this perception, there are some examples of successful social enterprises, especially in Serbia in the form of cooperatives. In most of the countries, 
this sector is within the CSOs sector and most of them are in the form of associations, mostly supported by foreign funding. Lastly, SEs use internal means of monitoring and/or donor-imposed reporting formats, but in Western Balkans this sector lacks systematic monitoring at a country level.

According to Rosandić and Kusinikova [19], in the country report for Kosovo of the European Commission, there are very few SEs in Kosovo and their size is very small. They have been created with donor funding but their financial situation is unsustainable which means that they are not able to continue their operations without continuous grant funding. Most of them are supported by foreign donor programs such as the European Commission, World Bank, USAID, UNDP, IOM, UNV, GIZ, The Danish Refugee Council, et al., private foundations and bilateral donors, central and municipal government funds in a lower scale. Hence, the concept of the social economy in Kosovo is not properly understood and addressed. The fact that SEs are highly dependent on grants and there is no focus in their development stability, damages this sector for the long term. Another type of organization in this regard, agricultural cooperatives, in Kosovo are regulated under the law on agricultural cooperatives which is not related to CSO's or Civic Society. However, several business entities could potentially develop as social enterprises, and Rosandić and Kusinikova regard them as a serious potential for being such, although they were not built on these premises.

\section{Conclusions and future study}

Although it is difficult to completely separate the character of CSOs, we can still say that as elsewhere, even in Kosovo, civil society organizations have their major focus on social issues. This makes it even more difficult to understand precisely what their contribution to overall economic activity is, thus this paper attempts to make a separate breakdown of organizations directly related to economic activities, especially agriculture.

In Kosovo, most of the NGOs were established in urban areas and their contribution to employment seems to be symbolic. The number of established NGOs on various areas related to economic activities, including the big sector of agriculture, over the past 20 years exceeded 1500 , or around $15 \%$ of the total. Mostly funded by foreign donors, there are cases of NGO's which notably brought significant improvements to agriculture. In another form of organization which can be seen under the scope of CSOs, social enterprises, that attempted to be artificially installed in Kosovo, are now heading towards extinction due to numerous problems such as development instability, dependence on funds and lack of understanding in their concept. However, there are also other forms of organizations which have similarities with CSOs but are in the business sector, such as agricultural cooperatives.

The lack of official complete and up-to-date data makes scientific studies even less. This remains the main issue in the study of CSOs not only in Kosovo, but almost all countries in the region have the same problem. Another conjoint problem is that even the existing data are very incomplete because they only show some basic information that is not detailed enough to be decent for a proper study. For subsequent future studies in this field, it is recommended that the work be based on primary sources for two crucial reasons. To discover the real number of active organizations and to obtain a broader set of information. Finally, due to the uncertainties in the various terminologies used for CSO's, for future studies, it is suggested to elaborate and establish a solid understanding of their key concepts. 


\section{References}

[1] L.M. Salamon - H.K. Anheier (1996) The International Classification of Nonprofit Organizations: ICNPO-Revision, Working Papers of the Johns Hopkins Comparative Nonprofit Sector Project, no. 19. Baltimore, 2-3.

[2] L. Gordenker - T. Weiss (1995) Pluralising global governance: analytical approaches and dimensions, Third World Quarterly Vol. 16 (No. 3), 358-387.

[3] A. Evers - J.-L. Laville, (2004) The Third Sector in Europe, 1-42.

[4] D. Lewis (2005) Actors, ideas and networks: trajectories of the non-governmental in development studies, in U. Kothari (ed.), A Radical History of Development Studies, London.

[5] W.E. Murray, - J.D. Overton (2011), Neoliberalism is dead, long live neoliberalism? Neostructuralism and the international aid regime of the 2-000s, Progress in Development Studies, 307-319.

[6] D. Lewis (2009) Non-governmental organisations (NGOs):definition and history, The International Encyclopaedia of Civil Society, edited by Helmut K. Anheier and Stefan Toepler, Springer, 7-8.

[7] N. Banks - D. Hulme (2012) The role of NGOs and civil society in development and poverty reduction, BWPI Working Paper 171, Brooks World Poverty Institute, University of Manchester, 5-6.

[8] L.M. Salamon - H.K. Anheier - R. List - S. Toepler - S. W. Sokolowski and Associates (1999) Global Civil Society - Dimensions of the Nonprofit Sector, The Johns Hopkins Center for Civil Society Studies, Baltimore, 8-10.

[9] L.M. Salamon - S. W. Sokolowski and Associates (2010) Global Civil Society: Dimensions of the Nonprofit Sector, 3rd ed., Kumarian Press, Greenwich.

[10] A.J. Bebbington - S. Hickey - D. Mitlin (2008) Introduction: can NGOs make a difference? The challenge of development alternatives, Zed Books, London, 3-37.

[11] M. Saunders - P. Lewis - A. Thornhill (2017) Research Methods for Business Students, 7th ed., Pearson, Harlow.

[12] E. Babbie (2014) The Practice of Social Research, 14th ed., Cengage Learning, Boston.

[13] Ministry of Public Administration (MPA), Government of Kosovo, Accessed 2019, from Electronic system of non-governmental organizations.

[14] D. Puka (2018) Kosovar Index of Civil Society, Kosovar Civil Society Foundation (KCSF).

[15] Kosovo Pension Savings Trust (2019) Annual Report of 2018, Fondi i Kursimeve Pensionale të Kosovës, Prishtinë.

[16] Initiative for Agricultural Development of Kosovo (2011-2012), Accessed 2019 from webpage: http://www.iadk.org/en-us/home.aspx 
[17] Initiative for Agricultural Development of Kosovo IADK (2018) Annual Report, Accessed 2019 from http://www.iadk.org/Portals/0/Raporte/Raporti vjetor IADK 2018 en.pdf

[18] A. Rosandić (2018) Social Economy in Eastern Neighbourhood and in the Western Balkans, Synthesis Report, AETS Consortium, European Commission, 9-10.

[19] A. Rosandić - N. Kusinikova (2018) Social Economy in Eastern Neighbourhood and in the Western Balkans, Country Report - Kosovo, AETS Consortium, European Commission. 